\title{
The Effect of Adiposity Markers on Fractional Exhaled Nitric Oxide (FeNO) and Pulmonary Function Measurements
}

This article was published in the following Dove Press journal: International Journal of General Medicine

\author{
Noor Al Khathlan (D)' \\ Ayad Mohammed Salem (D) ${ }^{2}$ \\ 'Respiratory Care Department, College \\ of Applied Medical Sciences, Imam \\ Abdulrahman Bin Faisal University, \\ Dammam, Saudi Arabia; ${ }^{2}$ Department of \\ Physiology, College of Medicine, Imam \\ Abdulrahman Bin Faisal University, \\ Dammam, Saudi Arabia
}

Background: The effect of increasing body weight on pulmonary function and the fractional exhaled nitric oxide (FeNO) remains controversial and the role of different body compositions in the relationship between obesity with pulmonary function and FeNO is still unrevealed. Thus, we aim to determine the effect of overweight/obesity on lung function and FeNO, focusing on the relationship with different body compositions.

Methods: Eighty-two non-smoker students (20 \pm 1.9 years) were divided into two groups: 38 subjects with normal weight $(\mathrm{BMI}=18.5-24.99)$ and 44 overweight/obese subjects (BMI $\geq 25$ ). Spirometric parameters and FeNO were measured and compared between groups and were correlated with different adiposity markers.

Results: FeNO measurements were elevated in the overweight/obese group [median (IQR) 19.5 (13)] in comparison to the normal weight group [11 (10), $\mathrm{p}$ value $=0.017]$. A positive correlation was found between FeNO measurements and body mass index (BMI), waist circumference, hip circumference, waist-hip ratio, and visceral fat percentage (all $\mathrm{p}$ values $<0.01$ ). The absolute values of forced vital capacity (FVC) forced expiratory volume in the first second $\left(\mathrm{FEV}_{1}\right)$, peak expiratory flow $(\mathrm{PEF})$, forced expiratory flow during mid-expiration $\left(\mathrm{FEF}_{25-75 \%}\right)$, and $\mathrm{FEV}_{1} / \mathrm{FVC}$ ratio showed no significant differences between groups. However, the percentage of the predicted values of $\mathrm{FEV}_{1}$ and $\mathrm{FVC}$ was significantly higher and the value of percentage predicted $\mathrm{FEF}_{25-75 \%}$ was reduced significantly in the overweight/obese subjects.

Conclusion: Increase in BMI could significantly increase airway inflammation as measured by FeNO, as well as on distal airway function as determined by the percentage predicted values of $\mathrm{FEF}_{25-75 \%}$. A significant correlation was also identified between visceral fat and FeNO measurement.

Keywords: BMI, obesity, FeNO, pulmonary function, body compositions
Correspondence: Noor Al Khathlan Email naalkathlan@iau.edu.sa

\section{Introduction}

Overweight and obesity have been increased dramatically since 1980, with estimated global prevalence of approximately $36.9 \%$ in men and $38.0 \%$ in women. ${ }^{1}$ Individuals with obesity are at increased risk of developing asthma and many respiratory symptoms. ${ }^{2}$ Increasing body weight could impair lung functions in different ways, the mechanical load of body fat decreases lung compliance leading to reduction of lung volumes, distal airway closure, expiratory flow limitation and overall limitation of exercise capacity. ${ }^{3}$

In addition, obesity has been considered as an inflammatory condition, adipose tissue is a source of many inflammatory cytokines such as leptin, adiponectin, IL-6, 
TNF- $\alpha$, which can play a role in obesity-related airway inflammation either directly or through immunological response. ${ }^{4}$ Excessive food intake of glucose and fat-rich diets may also contribute to increased oxidative stress and inflammation. $^{5}$

Nitric oxide (NO) is a free radical and a signaling molecule in different body cells. Nitric oxide in exhaled air is produced by airway epithelium and is considered a useful marker of airway inflammation in many pulmonary diseases, it was found that nitric oxide in exhaled breath (FeNO) showed high levels in patients with allergic respiratory diseases (ie, asthma, allergic rhinitis and alveolitis), cystic fibrosis, chronic obstructive pulmonary diseases (COPD), and pulmonary hypertension. ${ }^{6}$ In addition, FeNO was found to be increased in interstitial lung diseases as a results of nitrosative stress. ${ }^{7}$ Obesity may be associated with increased FeNO production in different ways. Adipose tissue has the ability to produce many pro-inflammatory adipokines which, in turn, can cause the inflammation of airways and remodeling structural changes. ${ }^{4}$ Apart from the inflammatory mediators, breathing at low lung volume can cause mechanical stress by frequent dilation and closure of small airways during breathing cycle, potentially leading to some degree of inflammation and hyperresponsiveness. ${ }^{8}$

The relationship between body mass index (BMI) and FeNO levels has not been comprehensively studied at this time, with extant studies reporting variable results. Some previous studies have not shown any differences in FeNO associated with overweight and obesity, ${ }^{9-12}$ others have reported low levels of FeNO in individuals with obesity, ${ }^{13,14}$ while a number of studies have reported increased FeNO production in adults and children with increased body weight. ${ }^{15-20}$ These discrepancies might be attributable to the use of different adiposity markers and the failure to control for the many confounders that can potentially affect FeNO. In addition, there is scarcity in the literature evaluating the effect of body compositions on exhaled NO and pulmonary function.

We hypothesized that body weight could impair pulmonary function and increase airway inflammation as measured by FeNO. Therefore, we aim to evaluate the effect of overweight and obesity on the pulmonary function and FeNO using a combination of BMI and body composition variables (total fat $\%$, visceral fat $\%$, and muscle mass \%) as adiposity markers.

\section{Subjects and Methods}

The study was conducted at the respiratory care department, College of Applied Medical Sciences, Imam Abdulrahman Bin Faisal University. Eighty-two non-smoker students (20 \pm 1.9 years) were recruited by convenience sampling from different colleges. After reviewing the medical history of each participant, we excluded those subjects with asthma, allergic rhinitis, chronic lung diseases, respiratory infection within the 4 weeks immediately prior to enrolment, pregnancy, and those who using bronchodilators or antiinflammatory drugs within 7 days of enrolment. This study followed the principle of the Declaration of Helsinki 1995 (revised in 2013). ${ }^{21}$ Ethical approval was granted for the study by the institutional review board - Imam Abdulrahman Bin Faisal University (IRB-2019-03-032). All participants had been informed about the purpose of the study and written consents were obtained before enrollment.

\section{Study Design}

This is a comparative cross-sectional study with two groups: Normal weight group (subjects with BMI $=18$.$5-24.99, \mathrm{n}=38$ ) and overweight/obese group (subjects with $\mathrm{BMI} \geq 25, \mathrm{n}=44)^{22}$

\section{Procedures}

All participants were undergone the following tests: anthropometric measurements, FeNO measurement, and spirometry. FeNO measurement was done before spirometry to avoid any confounding effect of forced exhalation on the level of nitric oxide in the exhaled air.

\section{Adiposity Measurements and Body Composition}

Subjects were measured for weight and height, while barefoot and wearing light clothing, to the nearest $0.1 \mathrm{~kg}$ and $0.1 \mathrm{~cm}$, using a digital Secca electronic scale and a Secca stadiometer, respectively. BMI was calculated as $(\mathrm{kg} / \mathrm{m} 2) .{ }^{22}$

Waist circumference (WC) was measured in a standing position after normal expiration, with the measurement taken at the middle level between the lower rib and the iliac crest. ${ }^{23}$ Hip circumference (HC) was measured at the widest part of the hip bones (the maximum circumference over the buttocks) in centimeters to the nearest $0.0-0.5 \mathrm{~cm}$. Waist-hip ratio (WHR) was calculated as WC divided by HC. Body fat percentage, visceral fat level, and muscle mass percentage by means of bioelectrical impedance 
analysis using an Omron body composition analyzer BF500 (Tokyo, Japan). ${ }^{24}$

\section{Fractional Exhaled Nitric Oxide (FeNO) Measurement}

The measurements of FeNO was done according to guidelines of the American thoracic society (ATS) ${ }^{25}$ using a handheld chemiluminescence $\mathrm{NO}$ analyzer (Niox Vero ${ }^{\circledR}$ Aerocrine AB, Solna, Sweden). The mean value of two exhalations at flow of $50 \mathrm{~mL} / \mathrm{s}$ was used for the analysis. Subjects were instructed not to exercise 1 hour before measurement and to avoid consumption of nitrate-rich foods (eg, Sausage, spinach, cauliflower) 3 hours before measurement.

\section{Spirometry}

Spirometry was performed following ATS guidelines for standardization of spirometry, ${ }^{26}$ using a calibrated computerized pneumatograph spirometer $\left(\right.$ Vitalograph $\left.{ }^{\circledR}\right)$. The absolute and percentage of predicted values of forced vital capacity (FVC), forced expiratory volume in the 1st second $\left(\mathrm{FEV}_{1}\right)$, forced expiratory flow at $25-75 \%\left(\mathrm{FEF}_{25-75 \%}\right)$, $\mathrm{FEV}_{1} / \mathrm{FVC}$ ratio, and peak expiratory flow (PEF) were calculated automatically based on age, sex, height and ethnicity, the predicted values for study participants were calculated based on Hankinson et al reference equations. ${ }^{27}$ Each subject has done three accepted maneuvers and then the highest values were recorded and used in the subsequent analyses.

\section{Statistical Analysis}

As most variables did not show normal distribution, the data were presented as median with interquartile range (IQR), variables showed normal distribution were presented as mean with standard deviation (SD). Unpaired $t$-test and Mann-Whitney $U$-test were used to compare continuous normally and non-normally distributed data, respectively. Chi-square test was used for comparisons of categorical variables. The Spearman's rank correlation coefficient $(r s)$ was used to investigate the relationship between adiposity markers (BMI, HC, WC, WHR, total fat \%, visceral fat $\%$, muscle \%) and FeNO measures. We determined the sample size of 30 subjects in each group based on many previous studies investigating the correlation between overweight and obesity with FeNO., ${ }^{911,14,28}$ The number of subjects in these studies ranged between 34 and 117 participants.

SPSS statistical package version 20.0 for Windows was used for the analyses and a p-value $<0.05$ was considered statistically significant.

\section{Results}

This study was conducted on 82 university students who fulfilled the eligibility criteria for recruitment. Out of these 82 subjects, $42(51.2 \%)$ were males and $40(48.8 \%)$ were females. Mean age of the patients was (20.3 \pm 1.9 years). A flow diagram of the participants is illustrated in (Figure 1). The main characteristics of each study group can be seen in (Table 1). Thirty-eight subjects had a normal BMI (mean \pm SD $21.47 \pm 1.8$ ) and 44 subjects were overweight/ obese (BMI $32.13 \pm 5.2$ ). At baseline, all anthropometric and body composition values were found to be significantly different between groups except age, gender and height (Table 1).

\section{Fractional Exhaled Nitric Oxide (FeNO)}

FeNO measurements were elevated in the overweight/ obese group [median (IQR) 19.5 (13)] compared to the normal weight group [median (IQR) $11(10), p=0.017$ ] (Table 2).

\section{Spirometric Measurements}

The absolute values of $\mathrm{FEV}_{1}, \mathrm{FVC}, \mathrm{FEV}_{1} / \mathrm{FVC}$ ratio, PEF, and $\mathrm{FEF}_{25-75 \%}$ showed no significant differences between groups. However, the percentage predicted values of the forced expiratory volume in 1 second $\left(\mathrm{FEV}_{1} \%\right.$ pred) and the forced vital capacity (FVC\% pred) showed significantly higher values in the overweight/obese group compared to the normal weight group. The percentage predicted values of the forced expiratory flow (FEF) during the middle portion of a forced expiration $\left(\mathrm{FEF}_{25-75 \%}\right.$ $\%$ pred) were significantly lower in the overweight/obese group than the normal weight group [median (IQR) 80 (19) vs 87 (20) respectively, $p=0.037$ ] (Table 2).

\section{Correlation Between Exhaled Nitric Oxide with Anthropometric and Body Composition Measurements}

FeNO measurements were positively correlated with BMI $\left(r_{s}=\right.$ $0.30, p=0.006$, waist circumference $(r s=0.38, \mathrm{p}=0.001)$, hip circumference $(r s=0.31, \mathrm{p}=0.005)$, waist-hip ratio $(r s=0.34$, $\mathrm{p}=0.006)$, and visceral fat percentage $(r s=0.30, \mathrm{p}=0.006)$. No significant correlation was observed with total body fat percentage and muscle percentage (Table 3).

\section{Discussion}

We studied the effects of obesity measurements on airway function and airway inflammation. We demonstrated low 


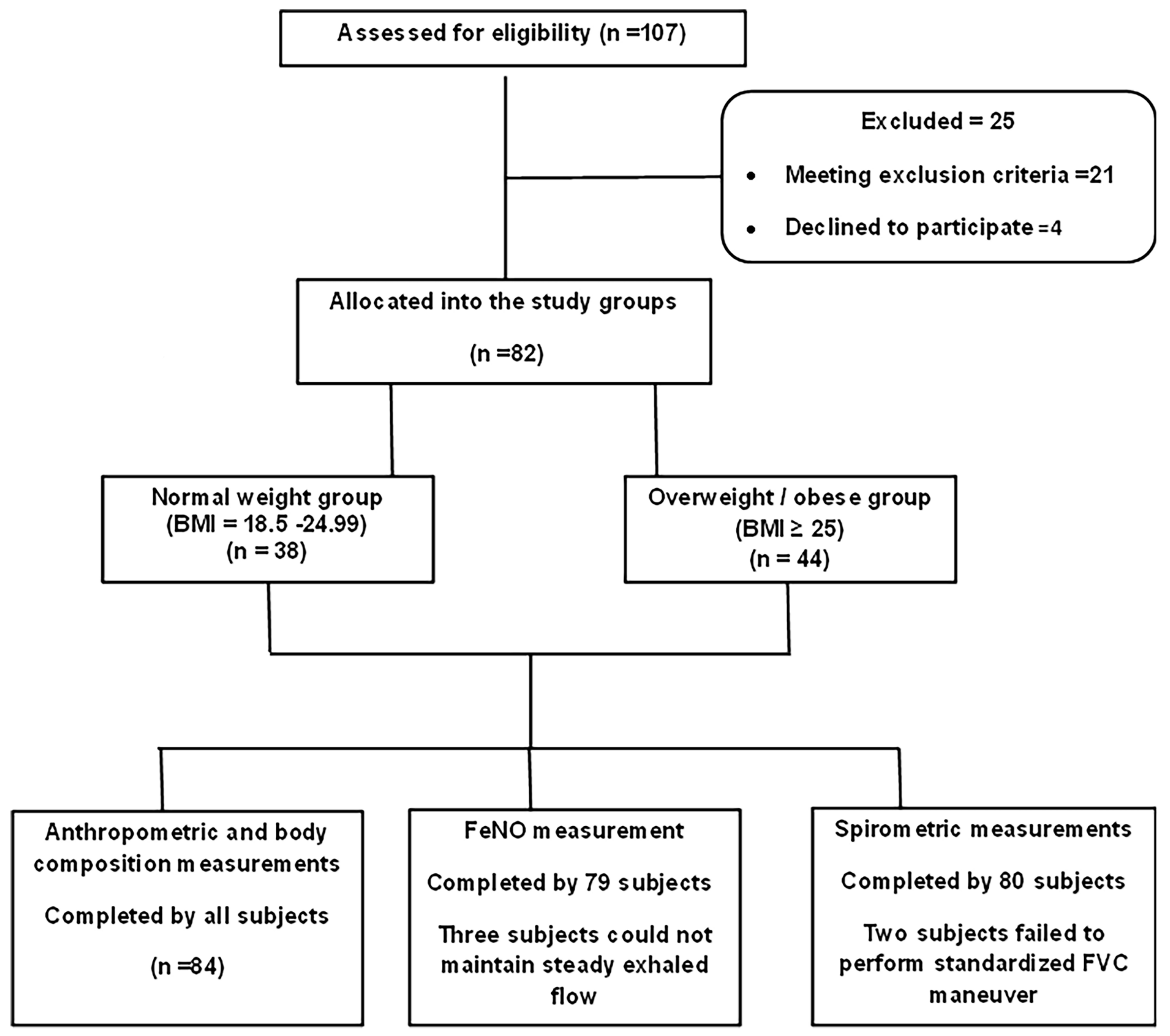

Figure I Study flow chart.

percentage predicted values for $\mathrm{FEF}_{25-75 \%}\left(\mathrm{FEF}_{25-75 \%} \%\right.$ pred) in overweight/obesity group as compared to participants with normal body weight. This pointed to defect in the small airways function which is measured by the $\mathrm{FEF}_{25-75 \%}{ }^{29}$ We also demonstrated the possibility for being overweight to influence airway inflammation, since high levels of FeNO were observed in over-weight/obese subjects compared to normal weight subjects.

\section{Effect on Airflow Limitation and Spirometric Variables}

Obesity can cause increased stiffness of the lung and thoracic wall, leading to reduced respiratory compliance. ${ }^{30}$ Increase body weight has been found to be negatively correlated with respiratory system compliance. ${ }^{31,32}$ The mechanical theory attributes the reduction in lung compliance to the compression of the respiratory system by excess body weight, causing decrease in lung volumes, mainly expiratory reserve volume (ERV) and functional residual capacity (FRC). ${ }^{33}$ In general, despite the reduction in respiratory compliance and lung volumes, obesity does not decrease $\mathrm{FEV}_{1}$ or FVC unless patients are massively obese (BMI $\geq 40$ ), $\mathrm{FEV}_{1}, \mathrm{FVC}$ and $\mathrm{FEV}_{1} / \mathrm{FVC}$ ratio are typically within the normal range or even increased. ${ }^{3,33}$ This could explain the higher $\mathrm{FEV}_{1 \%}$ pred and FVC \%pred observed in the overweight/obese group of our study since the mean BMI was (32.13 \pm 5.20$)$.

Obesity also causes increase airway resistance, and this is at least partly related to breathing at low lung volumes, 
Table I Descriptive Criteria of the Study Groups

\begin{tabular}{|l|l|l|l|}
\hline Variables* & $\begin{array}{l}\text { Normal Weight Group } \\
\mathbf{n}=\mathbf{3 8}\end{array}$ & $\begin{array}{l}\text { Overweight/Obese Group } \\
\mathbf{n}=\mathbf{4 4}\end{array}$ \\
\hline Age (years) & $20 \pm 1$ & $20 \pm 1.9$ & $\mathbf{P}$ value \\
Gender n (M/F) & $(19 / 19)$ & $(23 / 21)$ & 0.943 \\
Weight (kg) & $57.5(10.7)$ & $85.9(29.2)$ & 0.837 \\
Height (cm) & $165(11.5)$ & $165(15)$ & 0.000 \\
BMl & $21.5 \pm 1.8$ & $32.1 \pm 5.2$ & 0.772 \\
WC (cm) & $72.5(8.8)$ & $94.5(27)$ & 0.000 \\
HC (cm) & $93.5(6.3)$ & $114(18.5)$ & 0.000 \\
WHR & $0.78(0.08)$ & $0.84(0.15)$ & 0.000 \\
Body fat \% & $25(17)$ & $44(11)$ & 0.002 \\
Body Muscles \% & $33(16)$ & $25.60(10)$ & 0.000 \\
Visceral fat \% & $4(1)$ & $7.5(7)$ & 0.019 \\
\hline
\end{tabular}

Notes: *Values were presented as median with interquartile range (IQR) except age and BMI were presented as mean $\pm(\mathrm{SD})$ and gender was given as actual numbers (n). `Comparisons were done using Mann Whitney U-Test and unpaired $t$-test for non- normally and normally distributed continuous data respectively, and Chi-square test for categorical data.

Abbreviations: BMI, body mass index; WC, waist circumference; HC, hip circumference; WHR, waist/hip ratio.

Table 2 Comparison of Spirometric Measurements and Fractional Exhaled Nitric Oxide (FeNO) Values Between Study Groups

\begin{tabular}{|c|c|c|c|}
\hline Variables* & $\begin{array}{l}\text { Normal Weight Group } \\
\mathrm{n}=\mathbf{3 8}\end{array}$ & $\begin{array}{l}\text { Overweight/Obese Group } \\
n=44\end{array}$ & P value ${ }^{\wedge}$ \\
\hline $\mathrm{FeNO}(\mathrm{ppb})$ & II (I0) & $19.5(13)$ & 0.017 \\
\hline $\mathrm{FEV}_{1}(\mathrm{~L})$ & $3.2(0.8)$ & $3.4(0.9)$ & 0.280 \\
\hline FEV,\%pred & $91(13)$ & $95(17)$ & 0.009 \\
\hline FVC (L) & $3.9(1)$ & $4(1.1)$ & 0.475 \\
\hline FVC \%pred & $91(12)$ & $99(23)$ & 0.012 \\
\hline $\mathrm{FEV}_{\mathrm{l}} / \mathrm{FVC}$ ratio & $0.85(0.09)$ & $0.86(0.08)$ & 0.832 \\
\hline $\mathrm{FEV}_{1} / \mathrm{FVC} \%$ pred & $97(0.09)$ & $98(0.07)$ & $0.84 I$ \\
\hline PEF (L/sec) & $5.8(2)$ & $6(1.8)$ & 0.602 \\
\hline PEF \%pred & $86(34)$ & $87(34)$ & 0.321 \\
\hline FEF $_{25 \%-75 \%}(\mathrm{~L} / \mathrm{sec})$ & $3.7(1)$ & $3.6(1)$ & 0.370 \\
\hline FEF $25 \%-75 \%$ \%pred & $87(20)$ & $80(19)$ & 0.037 \\
\hline
\end{tabular}

Notes: *Values are presented as median with interquartile range (IQR). ^Comparisons were done using Mann Whitney U-Test.

Abbreviations: FeNO, fractional exhaled nitric oxide; FEVI, forced expiratory volume in I second; FVC, forced vital capacity; PEF, peak expiratory flow; FEF $25 \%-75 \%$, forced expiratory flow at $25-75 \%$; \%pred, percentage predicted value.

Table 3 Correlation Between Adiposity Markers and Fractional Exhaled Nitric Oxide (FeNO) Measurements

\begin{tabular}{|l|l|l|l|l|l|l|l|l|}
\hline \multicolumn{2}{|l|}{ Variables } & BMI & WC & HC & WHR & Body Fat \% & Muscles \% & Visceral Fat \% \\
\hline FeNO & $r_{\text {s }}$ & 0.30 & 0.38 & 0.31 & 0.34 & 0.07 & 0.15 & 0.37 \\
& p value* & $0.006^{*}$ & $0.00 I^{*}$ & $0.005^{*}$ & $0.002^{*}$ & 0.51 & 0.16 & $0.00 I^{*}$ \\
\hline
\end{tabular}

Notes: *Correlation done using Spearman's rank correlation coefficient (rs).

Abbreviations: FeNO, fractional exhaled nitric oxide; BMI, body mass index; WC, waist circumference; HC, hip circumference; WHR, waist/hip ratio.

leading to closure of the smaller airways. ${ }^{34}$ Despite the controversy about the role of $\mathrm{FEF}_{25-75 \%}$ in clinical practice, many recent literatures highlighted its role as a marker of small airways obstruction ${ }^{35}$ and as an early predictor for asthma onset and airways hypersensitivity even with normal $\mathrm{FEV}_{1}$ and $\mathrm{FEV}_{1} / \mathrm{FVC}^{36}$ The current study demonstrated an increased airflow limitation in small airways reflected by the reduction of $\mathrm{FEF}_{25-75 \%} \%$ pred while $\mathrm{FVC}$ and $\mathrm{FEV}_{1}$ were within normal range. This in line with a study investigating the relationship between obesity and spirometric variables in asthma where a significant number of patients with normal $\mathrm{FEV}_{1}$ had 
impaired mid-flow rates. ${ }^{37}$ Further support is coming from a recent study that found a positive correlation between small airways resistance (measured by impulse oscillometry (IOS) with adipose tissue volume and percentage). ${ }^{11}$ In addition, patients underwent bariatric surgery showed an improvement in small airways resistance measured by IOS with marked improvement in those with associated asthma, highlighting a possible involvement of small airways in the relationship between increase body weight and airways inflammation. ${ }^{38}$

However, Rubenstein et al have shown that individuals with obesity experience reduced expiratory flow at $\mathrm{FEF}_{25 \%}$, even after adjustment for lung volumes, which supports the possibility of distal airways obstruction by causes other than reduced lung volumes. ${ }^{39}$ Further evidence for this can be seen in studies of demonstrating persistence of distal airways abnormalities despite correction the lung volumes or even with increased lung volumes. Thus, the abnormal function of small airways observed in obesity could be explained by the presence of reduction in lung volumes due to functional mechanical restriction and/or a true pathological airways narrowing. ${ }^{40,41}$

These mechanisms should not be discussed separately, as breathing at a low lung volume could also have pathological consequences, inducing mechanical friction by frequent dilation and narrowing of distal airways during ventilation, which might lead to some degree of inflammation and hyperresponsiveness. ${ }^{8}$ In addition to inflammation caused by mechanical stress, the inflammatory origin of airways obstruction in individuals with obesity could also be explained by their exposure to inflammatory mediators. Obesity has been defined as an inflammatory disease and adipose tissue mass is considered an endocrine organ, with the ability to produce many pro-inflammatory adipokines, ${ }^{4}$ which in turn, could cause inflammation of airways and remodeling structural changes. Consequently, individuals with overweight/obesity are at higher risk of developing bronchial asthma. ${ }^{42}$ All these might augments the existence of persistent inflammation of the airways beside the reduction of airway diameter caused by mechanical loading.

\section{Effect of Overweight/Obesity on Airways Inflammation}

Non-invasive measurements of nitric oxide in the exhaled breath (FeNO) are considered a novel biomarker reflecting inflammation in the airways. ${ }^{6}$ Our study reports higher levels of FeNO in overweight/obese subjects. Nevertheless, there is some dispute about the effect of increasing BMI on FeNO, with certain previous studies either failing to show any differences in FeNO associated with overweight and obesity ${ }^{9-12}$ or only reporting low levels of FeNO in individuals with obesity. ${ }^{13,14}$ However, a number of studies support the results of our study, having identified increased levels of FeNO production among adults and children with increased body weight. ${ }^{15-20}$

It is important to note that FeNO is increased in the eosinophilic inflammation that characterizes the atopic Thelper asthma phenotype. ${ }^{43}$ Though obesity has been characterized by chronic non-eosinophilic inflammation of the airways, ${ }^{44}$ a concurrent airway eosinophilia was found in obesity-related airways inflammation. A murine model of obesity showed airway eosinophilia that could modulate the airway hyper-reactivity mediated predominantly by neutrophils. ${ }^{45}$ Airways inflammation with marked eosinophilia has also been observed in ob/ob leptin-deficient mice $^{46}$ and high-fat diet obese mice. ${ }^{47}$ Furthermore, a number of clinical studies showed increase in the eosinophilic airway's inflammation in obese asthmatic patients. ${ }^{44,48}$ Desai et al had detected an increased number of eosinophils at the airway wall of obese asthmatic patients. $^{49}$ That is why subjects with atopic asthma may have a more severe disease in the presence of obesity. ${ }^{50}$ Many inflammatory mediators produced by adipose tissue (adipocytokines and interleukins) have been shown to shift the immune status toward T-helper 2 phenotype, promoting the risk of developing allergic airways inflammation. ${ }^{51}$ Hence, it seems that both atopic (Th 2- dependent) and non-atopic airways inflammation could exist in association with obesity. In addition, recent studies suggest that FeNO better reflects the inflammation of local airways driven by a T-helper 2-mediated pathway, rather than generalized eosinophilic inflammation. ${ }^{52}$ Many evidences support the presence of some degree of low Th2 inflammation in obesity-related asthma. ${ }^{53}$ A new classification of asthma endotypes has emerged according to the degree of Th2 inflammation into: high Th2 and low Th2 subtypes, where obesity-related airway inflammation is considered as low Th2 subtype. ${ }^{54}$ This mechanistic classification (endotypes) gives a better understanding of the pathogenesis of asthma that was considered as Th2 independent inflammation. Furthermore, a potential factor why obesity can cause airways inflammation with elevated FeNO is the presence of co-morbid obstructive sleep apnea (OSA). OSA is very 
frequent in obesity and could lead to increased airway inflammation and FENO values. ${ }^{55}$

One of the strengths of the current study was the correlation between FeNO with many adiposity markers (BMI, WC, HC) and body compositions (total body fat percentage, visceral fat percentage and muscles percentage). In this way, we established a correlation between FeNO measurements and BMI, waist circumference and hip circumference, which is in line with some previous studies. ${ }^{15,16,30}$ Interestingly, our findings show a moderate to strong correlation between FeNO and the visceral fat percentage, but no correlation with the total fat percentage. This might reflect a detrimental role of visceral fat in the inflammation and narrowing of airways, thereby supporting the findings of a recent study on asthmatic patients investigating the association between airway measurements and the mass of visceral fat measured by computerized CT scan, in which found that abdominal visceral fat was correlated to bronchial luminal narrowing. ${ }^{56}$

We also acknowledge certain limitations inherent to this type of research. The cross-sectional design of the study makes it difficult to conclude a causal relationship between obesity and airway inflammation.

In a conclusion, the current study supports the evidences that obesity can significantly affect the function of the lung by means of obesity-induced airways inflammation beside the mechanical compression. Further studies investigating the mechanism of airways inflammation in obesity and its relation to body composition using gold standard invasive techniques such as broncho-alveolar lavage and bronchial biopsy are recommended.

\section{Acknowledgments}

This study was supported by the Deanship of Scientific Research at Imam Abdulrahman Bin Faisal University [grant number 2017-058-CAMS].

\section{Disclosure}

The authors declare that they have no conflicts of interest.

\section{References}

1. Ng M, Fleming T, Robinson M, et al. Global, regional, and national prevalence of overweight and obesity in children and adults during 1980-2013: a systematic analysis for the Global Burden of Disease Study 2013. Lancet. 2014;384(9945):766-781. doi:10.1016/S01406736(14)60460-8

2. Mahadev S, Farah CS, King GG, Salome CM. Obesity, expiratory flow limitation and asthma symptoms. Pulm Pharmacol Ther. 2013;26 (4):438-443. doi:10.1016/j.pupt.2012.05.004
3. Dixon AE, Peters U. The effect of obesity on lung function. Expert Rev Respir Med. 2018;12(9):755-767. doi:10.1080/17476348. 2018.1506331

4. Mancuso P. Obesity and lung inflammation. J Appl Physiol. 2010;108 (3):722-728.

5. Tan BL, Norhaizan ME, Liew WP. Nutrients and oxidative stress: friend or foe? Oxid Med Cell Longev. 2018;2018:9719584.

6. Barnes PJ, Dweik RA, Gelb AF, et al. Exhaled nitric oxide in pulmonary diseases: a comprehensive review. Chest. 2010;138 (3):682-692.

7. Cameli P, Bargagli E, Refini RM, Pieroni MG, Bennett D, Rottoli P. Exhaled nitric oxide in interstitial lung diseases. Respir Physiol Neurobiol. 2014;197:46-52.

8. Torchio R, Gobbi A, Gulotta C, et al. Mechanical effects of obesity on airway responsiveness in otherwise healthy humans. $J$ Appl Physiol. 2009;107(2):408-416.

9. Kim SH, Kim TH, Lee JS, et al. Adiposity, adipokines, and exhaled nitric oxide in healthy adults without asthma. J Asthma. 2011;48 (2):177-182.

10. Cibella F, Cuttitta G, La Grutta S, Melis MR, Bucchieri S, Viegi G. A cross-sectional study assessing the relationship between BMI, asthma, atopy, and eNO among schoolchildren. Ann Allergy Asthma Immunol. 2011;107(4):330-336.

11. van de Kant KD, Paredi P, Meah S, Kalsi HS, Barnes PJ, Usmani OS. The effect of body weight on distal airway function and airway inflammation. Obes Res Clin Pract. 2016;10(5):564-573.

12. Ekstrom S, Hallberg J, Kull I, et al. Body mass index status and peripheral airway obstruction in school-age children: a population-based cohort study. Thorax. 2018;73(6):538-545.

13. Komakula S, Khatri S, Mermis J, et al. Body mass index is associated with reduced exhaled nitric oxide and higher exhaled 8-isoprostanes in asthmatics. Respir Res. 2007;8:32. doi:10.1186/1465-9921-8-32

14. Maniscalco M, Zedda A, Faraone S, Cristiano S, Sofia M, Motta A. Low alveolar and bronchial nitric oxide in severe uncomplicated obesity. Obes Res Clin Pract. 2015;9(6):603-608.

15. Erkocoglu M, Kaya A, Ozcan C, et al. The effect of obesity on the level of fractional exhaled nitric oxide in children with asthma. Int Arch Allergy Immunol. 2013;162(2):156-162.

16. Uppalapati A, Gogineni S, Espiritu JR. Association between Body Mass Index (BMI) and fraction of exhaled nitric oxide (FeNO) levels in the National Health and Nutrition Examination Survey (NHANES) 2007-2010. Obes Res Clin Pract. 2016;10(6):652-658.

17. de Winter-de Groot KM, van der Ent CK, Prins I, Tersmette JM, Uiterwaal CSPM. Exhaled nitric oxide: the missing link between asthma and obesity? J Allerg Clin Immunol. 2005;115(2):419-420. doi:10.1016/j.jaci.2004.11.025

18. Carpagnano GE, Spanevello A, Sabato R, Depalo A, Turchiarelli V, Foschino Barbaro MP. Exhaled $\mathrm{pH}$, exhaled nitric oxide, and induced sputum cellularity in obese patients with obstructive sleep apnea syndrome. Transl Res. 2008;151(1):45-50. doi:10.1016/j.trsl.2007.09.004

19. Chow JS, Leung AS, Li WW, Tse TP, Sy HY, Leung TF. Airway inflammatory and spirometric measurements in obese children. Hong Kong Medical Journal = Xianggang Yi Xue Za Zhi. 2009;15 (5):346-352.

20. Tsang KW, Ip SK, Leung R, et al. Exhaled nitric oxide: the effects of age, gender and body size. Lung. 2001;179(2):83-91.

21. Association WM. World Medical Association declaration of Helsinki: ethical principles for medical research involving human subjects. JAMA. 2013;310(20):2191-2194.

22. Nuttall FQ. Body mass index: obesity, BMI, and health: a critical review. Nutr Today. 2015;50(3):117-128. doi:10.1097/NT.0000 000000000092

23. Hatipoglu N, Ozturk A, Mazicioglu MM, Kurtoglu S, Seyhan S, Lokoglu F. Waist circumference percentiles for 7- to 17-year-old Turkish children and adolescents. Eur J Pediatr. 2008;167 (4):383-389. doi:10.1007/s00431-007-0502-3 
24. Jackson AA, Johnson M, Durkin K, Wootton S. Body composition assessment in nutrition research: value of BIA technology. Eur J Clin Nutr. 2013;67(Suppl 1):S71-8.

25. Exhaled NO. ATS/ERS recommendations for standardized procedures for the online and offline measurement of exhaled lower respiratory nitric oxide and nasal nitric oxide, 2005. Am J Respir Crit Care Med. 2005;171(8):912-930.

26. Graham BL, Steenbruggen I, Miller MR, et al. Standardization of Spirometry 2019 update. An Official American Thoracic Society and European Respiratory Society technical statement. Am J Respir Crit Care Med. 2019;200(8):e70-e88. doi:10.1164/rccm.201908-1590ST

27. Hankinson JL, Odencrantz JR, Fedan KB. Spirometric reference values from a sample of the general U.S. population. Am J Respir Crit Care Med. 1999;159(1):179-187. doi:10.1164/ajrccm.159.1.97 12108

28. Zerah F, Harf A, Perlemuter L, Lorino H, Lorino AM, Atlan G. Effects of obesity on respiratory resistance. Chest. 1993;103 (5):1470-1476.

29. Marseglia GL, Cirillo I, Vizzaccaro A, et al. Role of forced expiratory flow at $25-75 \%$ as an early marker of small airways impairment in subjects with allergic rhinitis. Allerg Asthma Proc. 2007;28(1):74-78. doi:10.2500/aap.2007.28.2920

30. Salome CM, King GG, Berend N. Physiology of obesity and effects on lung function. J Appl Physiol. 2010;108(1):206-211. doi:10.1152/ japplphysiol.00694.2009

31. Pelosi P, Croci M, Ravagnan I, et al. The effects of body mass on lung volumes, respiratory mechanics, and gas exchange during general anesthesia. Anesth Analg. 1998;87(3):654-660.

32. Pelosi P, Croci M, Ravagnan I, Vicardi P, Gattinoni L. Total respiratory system, lung, and chest wall mechanics in sedated-paralyzed postoperative morbidly obese patients. Chest. 1996;109(1):144-151.

33. Littleton SW. Impact of obesity on respiratory function. Respirology (Carlton, Vic). 2012;17(1):43-49. doi:10.1111/j.1440-1843.2011. 02096.x

34. Watson RA, Pride NB. Postural changes in lung volumes and respiratory resistance in subjects with obesity. $J$ Appl Physiol. 2005;98 (2):512-517

35. Ciprandi G, Cirillo I. The pragmatic role of FEF25-75 in asymptomatic subjects, allergic rhinitis, asthma, and in military setting. Expert Rev Respir Med. 2019;13(12):1147-1151.

36. Sposato B, Scalese M, Migliorini MG, Di Tomassi M, Scala R. Small airway impairment and bronchial hyperresponsiveness in asthma onset. Allergy Asthma Immunol Res. 2014;6(3):242-251.

37. Ghabashi AE, Iqbal M. Obesity and its correlation with spirometric variables in patients with asthma. Med Gen Med. 2006;8(1):58.

38. van Huisstede A, Rudolphus A, Castro Cabezas M, et al. Effect of bariatric surgery on asthma control, lung function and bronchial and systemic inflammation in morbidly obese subjects with asthma. Thorax. 2015;70(7):659-667.

39. Rubinstein I, Zamel N, DuBarry L, Hoffstein V. Airflow limitation in morbidly obese, nonsmoking men. Ann Intern Med. 1990;112 (11):828-832.
40. Mahadev S, Salome CM, Berend N, King GG. The effect of low lung volume on airway function in obesity. Respir Physiol Neurobiol. 2013;188(2):192-199.

41. Oppenheimer BW, Berger KI, Segal LN, et al. Airway dysfunction in obesity: response to voluntary restoration of end expiratory lung volume. PLoS One. 2014;9(2):e88015.

42. Wieser V, Moschen AR, Tilg H. Inflammation, cytokines and insulin resistance: a clinical perspective. Arch Immunol Ther Exp (Warsz). 2013;61(2):119-125.

43. Dweik RA, Boggs PB, Erzurum SC, et al. An official ATS clinical practice guideline: interpretation of exhaled nitric oxide levels (FENO) for clinical applications. Am J Respir Crit Care Med. 2011;184(5):602-615.

44. Scott HA, Gibson PG, Garg ML, Wood LG. Airway inflammation is augmented by obesity and fatty acids in asthma. Eur Respir J. 2011;38(3):594-602.

45. Calixto MC, Lintomen L, Schenka A, Saad MJ, Zanesco A, Antunes E. Obesity enhances eosinophilic inflammation in a murine model of allergic asthma. Br J Pharmacol. 2010;159(3):617-625.

46. Lintomen L, Calixto MC, Schenka A, Antunes E. Allergen-induced bone marrow eosinophilopoiesis and airways eosinophilic inflammation in leptin-deficient ob/ob mice. Obesity. 2012;20(10):1959-1965.

47. Mito N, Kitada C, Hosoda T, Sato K. Effect of diet-induced obesity on ovalbumin-specific immune response in a murine asthma model. Metabolism. 2002;51(10):1241-1246.

48. Grotta MB, Squebola-Cola DM, Toro AA, et al. Obesity increases eosinophil activity in asthmatic children and adolescents. BMC Pulm Med. 2013;13:39.

49. Desai D, Newby C, Symon FA, et al. Elevated sputum interleukin-5 and submucosal eosinophilia in obese individuals with severe asthma. Am J Respir Crit Care Med. 2013;188(6):657-663.

50. Bhatt NA, Lazarus A. Obesity-related asthma in adults. Postgrad Med. 2016;128(6):563-566.

51. Hersoug LG, Linneberg A. The link between the epidemics of obesity and allergic diseases: does obesity induce decreased immune tolerance? Allergy. 2007;62(10):1205-1213.

52. Han YY, Forno E, Celedon JC. Adiposity, fractional exhaled nitric oxide, and asthma in U.S. children. Am J Respir Crit Care Med. 2014;190(1):32-39.

53. Fahy JV. Type 2 inflammation in asthma-present in most, absent in many. Nat Rev Immunol. 2015;15(1):57-65.

54. Kuruvilla ME, Lee FE, Lee GB. Understanding asthma phenotypes, endotypes, and mechanisms of disease. Clin Rev Allergy Immunol. 2019;56(2):219-233.

55. Bikov A, Hull JH, Kunos L. Exhaled breath analysis, a simple tool to study the pathophysiology of obstructive sleep apnoea. Sleep Med Rev. 2016;27:1-8.

56. Yang MS, Choi S, Choi Y, Jin KN. Association between airway parameters and abdominal fat measured via computed tomography in asthmatic patients. Allergy Asthma Immunol Res. 2018;10 (5):503-515.

\section{Publish your work in this journal}

The International Journal of General Medicine is an international, peer-reviewed open-access journal that focuses on general and internal medicine, pathogenesis, epidemiology, diagnosis, monitoring and treatment protocols. The journal is characterized by the rapid reporting of reviews, original research and clinical studies across all disease areas. The manuscript management system is completely online and includes a very quick and fair peer-review system, which is all easy to use. Visit http://www.dovepress.com/ testimonials.php to read real quotes from published authors. 